\title{
Publisher Correction: Automating turbulence modelling by multi-agent reinforcement learning
}

Guido Novati D, Hugues Lascombes de Laroussilhe and Petros Koumoutsakos (D)

Correction to: Nature Machine Intelligence https://doi.org/10.1038/s42256-020-00272-0, published online 4 January 2021.

In the version of this Article originally published, the captions of Figs. 2-6 were from different figures: Fig. 2 should have had the caption of Fig. 4, Fig. 3 the caption of Fig. 5, Fig. 4 the caption of Fig. 5, Fig. 5 the caption of Fig. 2, and Fig. 6 the caption of Fig. 3 . This has now been corrected in all versions of the Article.

Published online: 7 January 2021

https://doi.org/10.1038/s42256-021-00293-3

(c) The Author(s), under exclusive licence to Springer Nature Limited 2021 